\title{
O TEOR DE MATÉRIA GRAXA DA MANJUBA (Anchoviella hubbsi Hildebrand) DO RIO RIBEIRA DE IGUAPE
}

\author{
Masayuki Furuya
}

O grosso da produção de manjuba do Rio Ribeira de Iguape é destinado à salga. O produto salgado e sêco, tal como é apresentado ao mercado, é de curta durabilidade. Normalmente, quando não é conservado sob refrigeração, a manjuba salgada e sêca adquire côr marrom escura em dois ou três meses, podendo freqüentemente apresentar-se putrefata e transformada em pasto para larvas de môsca. Alguns industriais têm recorrido a recursos diversos, tais como a refrigeração e a utilização de latas como embalagem hermética, em substituição à de madeira, com o intuito de uniformizar a qualidade do produto e preservá-lo por período mais dilatado. Entretanto, quanto aos fatôres que influem sôbre a rapidez da deterioração, tudo permanece no terreno de conjeturas.

Entre as causas diretas da pequena durabilidade do produto poderíamos admitir a insuficiência da secagem, decorrente da falta de contrôle da umidade relativa, da temperatura e da velocidade de circulação do ar no interior do secador. Além dêsses fatôres, que são passíveis de contrôle, temos a considerar, ainda, outros decorrentes da própria espécie do peixe, entre êles o teor de gordura na carne.

Nessas condições, foi objeto do presente trabalho obter informações sôbre o teor de matéria graxa, quanto a diferenças locais e variação durante o período de safra, que se estende aproximadamente de outubro a março, visto que, a respeito, não temos conseguido outros senão os resultados das análises efetuadas com a manjuba salgada e sêca no Departamento da Produção Animal ${ }^{1}$.

\section{AMOSTRAS}

Em três datas diferentes do período de safra, que se estende de 1954 a 1955, foram colhidas amostras em Iguape, desemboca- 
dura do Rio Ribeira de Iguape, e em Registro, que são os extremos do trecho do rio onde se processa a pesca da manjuba. Os peixes foram colhidos diretamente das rêdes ou das canoas que os transportam, antes de atingirem o estado de "rigor-mortis", e enxutos com pano e papel absorvente. Foram colocados individualmente em saquinhos de plástico (polietileno) de $4 \mathrm{~cm}$ de largura e $17 \mathrm{~cm}$ de comprimento. Os saquinhos continham prèviamente de 6 a $12 \mathrm{~g}$ de sal comum. Introduzido o peixe, fechava-se a bôca do saquinho, dobrando-a 2-3 vêzes e prendendo-a com "clips". Conhecendo-se o pêso total inicial (plástico, sal e "clips"), obtinha-se, por pesagem posterior do todo com o peixe, o pêso dêste último.

Antes do saquinho de plástico, recorremos ao tubo de vidro com rôlha de borracha. Entretanto, o tubo de vidro, quando de comprimento e diâmetro condizentes com as dimensões do peixe, apresenta excessivo espaço vazio e, nessas condições, a salmoura formada com o sal e a água do próprio peixe é insuficiente para manter êste último inteiramente submerso, de modo a evitar a sua deterioração. Além do mais, o vidro quebrava-se freqüentemente, tendo-se constatado, também, que a rôlha de borracha não oferecia garantia contra o vazamento da salmoura. A tabela I relaciona os locais de coleta, a data e o número de exemplares.

\section{TABELA I}

Locais de pesca, datas e número de exemplares.

\begin{tabular}{|c|c|c|c|c|c|}
\hline \multirow{2}{*}{$\begin{array}{l}\text { Local de } \\
\text { captura }\end{array}$} & \multirow{2}{*}{ Data } & \multirow{2}{*}{ Amostra $n^{\circ}$} & \multicolumn{3}{|c|}{ No de exemplares } \\
\hline & & & Machos & Fêmeas & Total \\
\hline Registro & $\begin{array}{r}2 / 11 / 54 \\
6 / 12 / 54 \\
26 / 1 / 55\end{array}$ & $\begin{array}{l}R-1 \\
R-2 \\
R-3\end{array}$ & $\frac{11}{26}$ & $\frac{20}{19}$ & $\begin{array}{l}31 \\
51 \\
45\end{array}$ \\
\hline Iguape & $\begin{array}{r}2 / 11 / 54 \\
7 / 12 / 54 \\
26 / 1 / 55\end{array}$ & $\begin{array}{l}I-1 \\
I-2 \\
I-3\end{array}$ & $\frac{19}{22}$ & $\frac{27}{24}$ & $\begin{array}{l}46 \\
48 \\
46\end{array}$ \\
\hline
\end{tabular}

\section{MÉTODO DE DOSAGEM}

A extração da matéria graxa foi feita pelo extrator Sohxlet de $125 \mathrm{cc}$, segundo o procedimento adotado no Instituto Adolfo Lutz $^{2}$. Apenas, em lugar de utilizarmos a areia no preparo do material, recorremos ao sulfato de sódio anidro para não perdermos o líquido que escorre do peixe durante o tratamento. Adicionamos quantidade suficiente de sulfato para obtermos massa mais 
ou menos enxuta que pudesse ser transferida sem perdas para uma cápsula. Essa cápsula era então levada à estufa a $100^{\circ} \mathrm{C}$. Todo o extrato etéreo foi tomado como matéria graxa.

\section{SUFICIENCIA DA EXTRAÇÃO DE 8 HORAS}

A fim de nos certificarmos de que 8 horas de extração seriam de fato suficientes, ensaiamos três extrações sucessivas, aproximadamente de 8 horas cada. Os resultados constam da tabela II.

TABELA II

Rendimento da extração de 8 horas.

\begin{tabular}{|c|c|c|c|c|c|c|c|}
\hline \multirow{2}{*}{$\begin{array}{l}\text { Análise } \\
\text { n* }\end{array}$} & \multirow{2}{*}{$\begin{array}{c}\text { Total em } \\
24 \text { horas } \\
\text { (g) }\end{array}$} & \multicolumn{2}{|c|}{$\begin{array}{c}\text { 1* extracão de } 8 \\
\text { horas }\end{array}$} & \multicolumn{2}{|c|}{$\begin{array}{c}\text { 2a extracão de } 8 \\
\text { horas }\end{array}$} & \multicolumn{2}{|c|}{$\begin{array}{c}\text { 3" extração de } 8 \\
\text { horas }\end{array}$} \\
\hline & & (g) & $(\%)$ & (g) & $(5)$ & (g) & $(\%)$ \\
\hline 54 & 1,9747 & 1,9270 & 97,58 & 0,0299 & 1,51 & 0,0178 & 0,90 \\
\hline $66 / 1$ & 0,7986 & 0,7785 & 97,48 & 0,0174 & 2,18 & 0,0027 & 0,34 \\
\hline $66 / 2$ & 1,2038 & 1,1807 & 98,08 & 0,0150 & 1,25 & 0,0081 & 0,67 \\
\hline $118 / 1$ & 0,7001 & 0,6870 & 98,13 & 0,0099 & 1,41 & 0,0032 & 0,46 \\
\hline $118 / 2$ & 0,8458 & 0,8271 & 97,79 & 0,0145 & 1,71 & 0,0042 & 0,50 \\
\hline $119 / 1$ & 0,9014 & 0,8801 & 97,64 & 0,0160 & 1,78 & 0,0053 & 0,59 \\
\hline $119 / 2$ & 0,7862 & 0,7720 & 98,19 & 0,0105 & 1,34 & 0,0037 & 0,47 \\
\hline 124 & 1,2159 & 1,1928 & 98,10 & 0,0152 & 1,25 & 0,0079 & 0,65 \\
\hline $123 / 1$ & 0,3859 & 0,3827 & 99,17 & $(*)$ & - & 0,0032 & 0,83 \\
\hline 125 & 1,3775 & 1,3454 & 97,67 & 0,0189 & 1,37 & 0,0132 & 0,96 \\
\hline 126 & 1,1496 & 1,1296 & 98,26 & 0,0143 & 1,24 & 0,0057 & 0,50 \\
\hline
\end{tabular}

* A fração correspondente à $2^{*}$ extração está inclusa naquela correspondente à $1^{\text {*a }}$.

Vê-se que, nas primeiras 8 horas, consegue-se extrair de 97,5 a $98,0 \%$ do total extraído em 24 horas. Em 16 horas extrai-se mais de $99 \%$. Em vista disso, para não nos demorarmos demasiadamente, limitamos o tempo de extração a 10-12 horas.

\section{RESULTADOS}

a) Diferenças individuais. - Entre os indivíduos do mesmo lote encontramos diferenças de 7 a $9 \%$ entre os mínimos e os máximos; essas diferenças se reduzem para cêrca de $5 \%$ se considerarmos os exemplares do mesmo sexo. t̂sse fato deve ser levado em consideração na amostragem, quanto à quantidade a ser tomada, pelo menos no que diz respeito à matéria graxa. Na tabela III constam a distribuição de freqüência dos teores encontrados e os respectivos elementos estatísticos. Os machos são, em geral, mais gordos do que as fêmeas. 


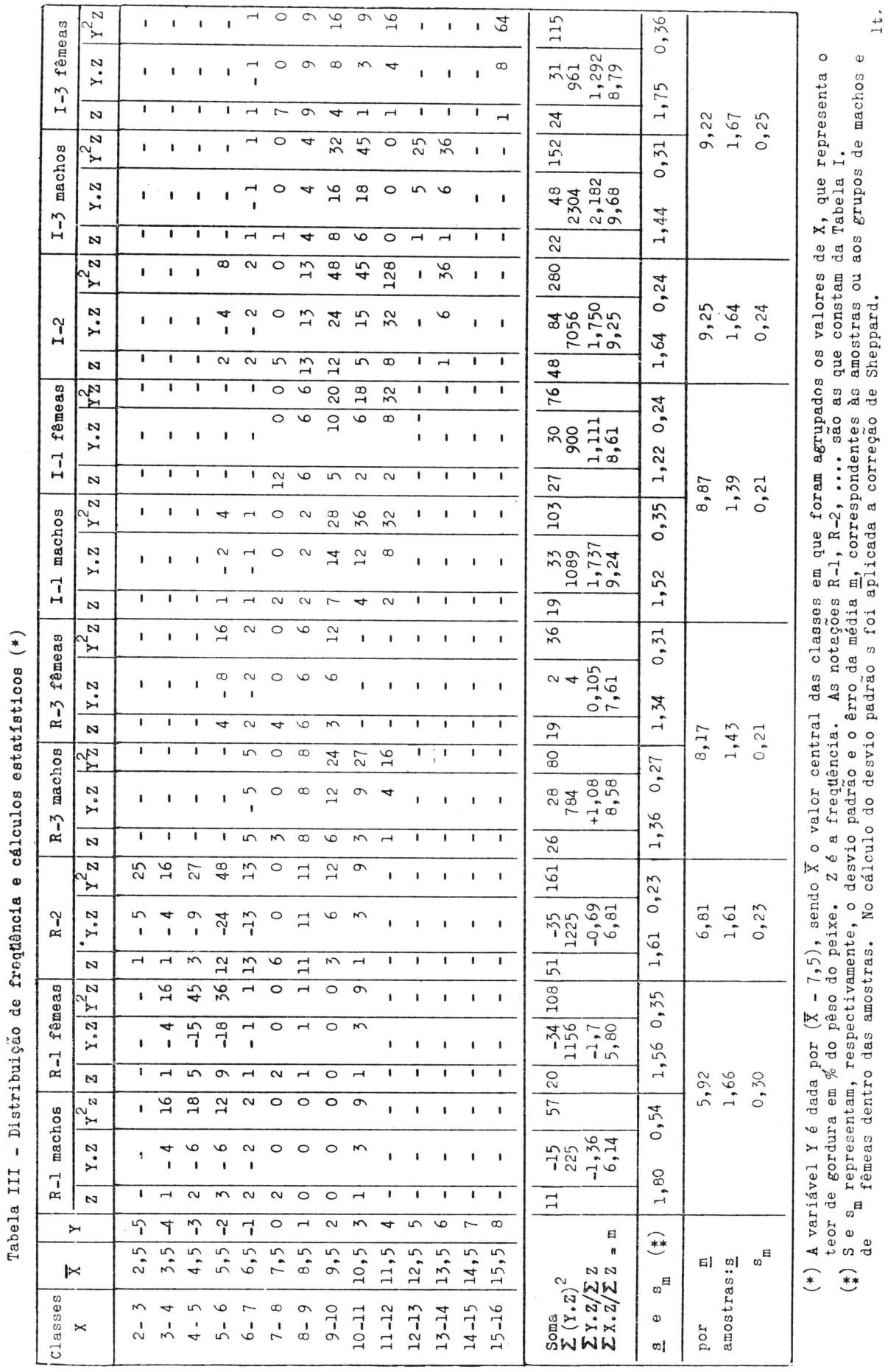




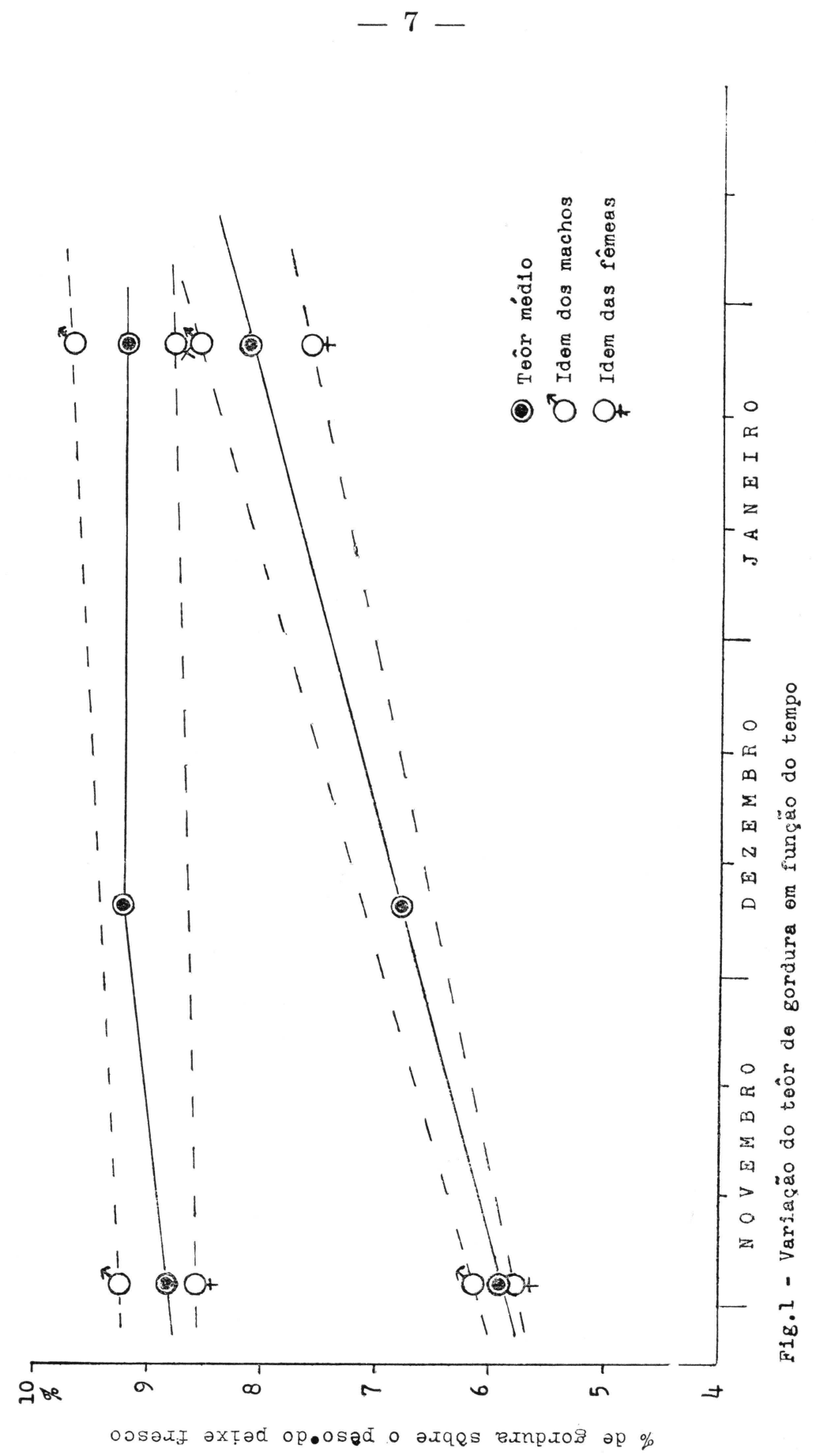


b) Diferenças locais. - Pelos dados da tabela III vê-se que, em Registro, encontramos sempre teores médios mais baixos de matéria graxa em relação aos das amostras de Iguape colhidas nas mesmas datas ou com um dia de diferença. Em Iguape não se observa alteração apreciável do teor médio de gordura, pelo menos nas três datas escolhidas. Nas amostras colhidas em Registro, nota-se que os seus teores médios crescem gradativamente com o correr dos meses, aproximando-se, aparentemente, dos resultados referentes a Iguape. A fig. 1 ilustra êsses fatos.

Havendo, entretanto, a possibilidade de não serem significativas as diferenças observadas entre os teores médios, procedemos à análise estatística. O recurso a que recorremos foi o da análise da variância ${ }^{3}$. Na tabela IV constam os resultados dos cálculos.

TABELA IV

\begin{tabular}{|c|c|c|c|c|}
\hline Procedência da variância & $\begin{array}{l}\text { Grau de } \\
\text { liberdade }\end{array}$ & $\begin{array}{l}\text { Soma dos } \\
\text { quadrados }\end{array}$ & Variância & F \\
\hline Entre as 10 coluna: $\ldots . .$. . & 9 & 455,0 & $50,6 "$ & $11,2 "$ \\
\hline "Registro vs. Iguape" ..... & 1 & 327,8 & $72,8^{\prime \prime}$ & $72,8 "$ \\
\hline Entre amostras de Iguape .. & 2 & 2,1 & 2,1 & 0,5 \\
\hline Entre amostras de Registro. & 2 & 98,5 & 49,3 & $11,0 "$ \\
\hline Machos vs. fêmeas em R-1. & 1 & 0,8 & 0,8 & 0,2 \\
\hline Machos vs. fêmeas em R-3 . & 1 & 10,4 & 10,4 & 2,3 \\
\hline Machos vs. fêmeas em I-1. & 1 & 4,3 & 4,3 & 1,0 \\
\hline Machos vs. fêmeas em I-3. & 1 & 9,0 & 9,0 & 2,0 \\
\hline Resíduo das somas $\ldots \ldots \ldots$ & 257 & $1.161,0$ & 4,5 & - \\
\hline Total .............. & 266 & $1.161,0$ & - & - \\
\hline
\end{tabular}

Pela tabela de F:

$$
\begin{array}{ll}
F_{257}^{9}(0,01)=2,49 ; & F_{257}^{1}(0,01)=6,74 \\
F_{257}^{1}(0,05)=3,88 ; & F_{257}^{2}(0,01)=4,70
\end{array}
$$

A notaç̃o" assinala os valores de F altamente significativos.

Verifica-se, então, que:

1) Entre as amostras de Registro e de Iguape, as diferenças entre os teores médios são significativas.

2) Entre as amostras de Registro, colhidas em datas diferentes, espaçadas de cêrca de um mês, existem diferenças significativas. Ao contrário, em relação às amostras de Iguape, colhidas nas mesmas condições, o resultado é negativo, podendo-se atribuir as diferenças havidas a erros acidentais. 
3) Entre os teores médios dos machos e das fêmeas, a diferença é significativa em Registro, ao passo que, estatisticamente, não se pode aventurar idêntica conclusão quanto ao exemplares de Iguape.

c) Distribuição no corpo do peixe. - Porções diferentes do corpo do peixe foram analisadas em separado. Os resultados apresentados na tabela $\mathrm{V}$ mostram a distribuição desigual de gordura

\section{TABELA V}

Distribuição de matéria graxa no corpo da manjuba, em \% do pêso da porção analisada (só a carne, exceto a cabeça).

\begin{tabular}{l|c|c|c|c|c}
\hline Cabeca & $\begin{array}{c}\text { Ventral } \\
\text { anterior }\end{array}$ & $\begin{array}{c}\text { Ventral } \\
\text { posterior }\end{array}$ & $\begin{array}{c}\text { Dorsal } \\
\text { anterior }\end{array}$ & $\begin{array}{c}\text { Dorsal } \\
\text { posterior }\end{array}$ & $\begin{array}{c}\text { Lateral } \\
(*)\end{array}$ \\
\hline 13,36 & 5,30 & - & 2,32 & 1,63 & 24,03 \\
\hline
\end{tabular}

(*) Carne sob a faixa prateada lateral.

no corpo do peixe. As percentagens citadas são referentes aos pêsos da carne salgada e, por isso, as proporções relativas entre elas não retratam necessàriamente aquelas existentes no peixe fresco, visto que, cada parte do corpo pode ter sofrido desidratação desigual por efeito do sal. Em todo o caso, é indubitável que a carne de côr marrom escura situada sob a faixa prateada da manjuba é bem mais rica em gordura do que o restante da carne que é branca.

\section{R E S U M O}

A Manjuba (Anchoviella hubbsi Hildebrand) da safra de outubro de 1954 a fevereiro de 1955 foi analisada em três datas distintas, espaçadas de, pelo menos, um mês quanto ao seu teor de matéria graxa, a fim de ser verificada a sua variação no tempo, por local de pesca e dentro de uma amostra.

1) Observou-se que a amplitude entre os valores extremos pode atingir, dentro da mesma amostra, a $7-9 \%$. Os valores extremos observados, dentro da totalidade das amostras foram de cêrca de $2,5 \%$ e ca. $15,5 \%$.

2) Os machos são, em regra, mais gordos do que as fêmeas.

3) Há diferenças significativas entre os teores médios de gordura dos exemplares procedentes de Registro e de Iguape. A diferença foi da ordem de $3 \%$ no principio da safra, tendo a mesma caído para ca. $1 \%$ ao fim da safra.

4) As amostras de Iguape não apresentaram diferenças significativas no decorrer da safra. Ao contrário, aquelas procedentes de Registro mostra- 
ram que o teor médio de gordura cresce gradualmente no decorrer dos meses, tendendo para um limite.

5) A carne escura situada sob a faixa prateada lateral é muito mais rica em gordura do que o restante da carne que é branca.

\section{AGRADECIMENTOS}

Às firmas Bento Neto, de Iguape, e N. Doi \& Cia., de Registro, consignamos os nossos agradecimentos pela colaboração que nos prestaram na aquisição dos peixes. Agradecemos, ainda, ao Sr. João de Paiva Carvalho pelos valiosos conselhos que nos possibilitaram melhorar a redação e a apresentação dêste trabalho.

Finalmente, assinalamos que, na efetivação das operações de laboratório, tiveram participação ativa os Srs. Clarimundo de Jesus e Orlando Manzini.

\section{S U M M A R Y}

The "Manjuba" (Anchoviella hubbsi Hildebrand) of the season October 1954 to February 1955 has been analyzed in three different dates, with at least a month's interval in order to verify the variation of fat content in relation to time and place of fishery and yet the variation in the sample.

1. The amplitude between the extreme values may reach in the same sample $7-9 \%$. The extreme values observed in the total of samples were of ca. 2.5 and ca. $15.5 \%$.

2. Males have, in general, a higher fat content than females.

3. There is a significant difference between the average fat content of the specimens from Registro and those from Iguape. The difference was as high as $3 \%$ at the beginning of the season, falling to ca. $1 \%$ at the end of it.

4. The samples from Iguape did not show any remarkable difference during the season. On the contrary, those from Registro showed that the average fat content increases gradually toward a limit as the months proceed.

5. The dark meat located under the lateral silver band is much richer in fat content than the white meat.

\section{B I B L I O G R A F I A}

1. Teixeira e Silva, H. M.

Dados não publicados da Seção de Industrialização e Conservação dos Produtos de Origem Animal, Departamento da Produção Animal, Secretaria da Agricultura do Estado de São Paulo.

2. Instituto Adolfo Lutz.

1951. Métodos de análises bromatológicas. I — Análises químicas, p. 314-5.

3. SNEdECOR, G. W.

1946. Statistical methods for Research Workers. 8th. edition. 485 p. 